\title{
CHANGING OF VISCOSITY AND THERMAL PROPERTIES OF OLIVE OIL WITH DIFFERENT HARVESTING METHODS AND WAITING PERIOD
}

\author{
Cihangir SAGLAM, Fulya TAN, Turkan AKTAS
}

\begin{abstract}
The aim of this paper is to determine how different harvesting methods of olives and the waiting period before the extraction of the extra virgin olive oil affect the viscosity and some thermal properties, namely thermal conductivity and thermal resistivity. Olive trees in the Aegean region of the western part of Turkey were harvested by using six different harvesting methods: by hand, harvesting by a beating pole on a synthetic fabric, harvesting by a beating pole on a platform, harvesting by machine on a synthetic fabric, harvesting by machine on a platform and direct collecting of dropped olives by hand. Olive oil samples were obtained in certain intervals between the harvesting and processing that was made by using a laboratory type system. The viscosity values of oil samples were measured by using a vibro-viscometer. The thermal conductivity and thermal resistivity of oil samples were measured simultaneously by using the KD2 Thermal properties analyzer. As a result, viscosity, thermal conductivity and thermal resistivity values changed related to the harvesting method and the waiting period after harvesting to obtain olive oil. While viscosity (dynamic) and thermal conductivity values increased with the increase of the waiting time, thermal resistivity values decreased. The lowest viscosity and thermal conductivity values and the highest resistivity values were found for oils that were obtained from olives harvested by hand.
\end{abstract}

Keywords: dynamic viscosity; extraction time; harvesting methods; olive oil; thermal conductivity; thermal resistivity

\section{INTRODUCTION}

Olives are traditionally hand harvested, a process that is not only tedious and laborious, but represents the major proportion of the costs of production. Harvesting by hand is accomplished by three techniques: collection of the fallen fruit from the ground, "milking", or the stripping of fruit with half open hands from limbs which fall into picking bags or onto nets below the tree, and beating limbs with large sticks to dislodge fruit, which is also collected on nets. Mechanical harvest of olives has been used to a limited extent in more intensive orchards.

As it is known, the harvesting method has an important effect on the quality of olives, especially in the production for table consumption. Some researchers showed that the harvesting method also has an important effect on the quality of olive oil. Although a number of studies have reported the effects of irrigation on yield parameters under conditions and varieties, there is a shortage of the influence of the harvesting method on oil quality. The effect of irrigation on the oil quality of the fruit obtained from both the mechanical and hand harvesting methods in addition to the yield parameters was also researched [4]. They found that when fruit was picked carefully by hand so that no injuries were inflicted, free fatty acids levels were substantially reduced, peroxide was reduced and the total polyphenol content was increased.

The degradation of oil quality related to increased irrigation could potentially be aggravated by damage to the fruit caused during harvesting. It was reported that the effect of the temperature on the experimental data on thermal conductivity and dynamic viscosity of some vegetable oils such as cotton seed, rice and corn in addition to olive oil was present [2]. They found that the thermal conductivity decreased slightly with the increase in temperature for all samples researched. Moreover, they reported that a rise in temperature led to a sharp decrease for this property for all samples.

The greatest deterioration of olive oil is due to the poor handling of olives during the time between harvesting and processing. The storage of olive fruits is carried out by simple heaping in fruit piles while they wait for their processing. These fruits develop all kinds of degenerative processes in a short period. Oil samples obtained from them show characteristics of hydrolytic and oxidative deteriorations confirmed by their high acidity values, or the peroxide value. To avoid this situation, the industry is currently reducing the interval between harvesting and processing through an increase in the milling capacity [5].

For this reason, olives should be crushed within the first 24 or 36 hours after picking. In spite of this situation, in many olive production countries, the waiting period between harvesting and processing has been longer than this mentioned period.

The viscosity value of a liquid is an important parameter for designing the piping in a plant, or transporting crude oil or a chemical agent through a pipeline. Measuring the viscosity has played an important role in, to say nothing of the petrochemistry industry, a wide range of industries such as the food, printing (ink), medical drug, or cosmetics industries, as well as in the quality control during a production process or in various research and development stages for the improvements of quality and performance.

The oxidative stability of oils is determined by thermal analyses. For this reason, thermal properties of oils are important factors that are evident of oxidation.

The increase of viscosity in olive oil shows the increase of the lipid oxidation [3]. Furthermore, the increase of thermal conductivity, namely decrease of thermal resistivity shows the low thermal stability and increase of lipid oxidation in oil. For this reason, the aim of this paper is to determine how the harvesting methods of olive and the waiting period 
before the extraction of the extra virgin olive oil affect the viscosity and certain thermal properties, namely the thermal conductivity and thermal resistivity of olive oil.

\section{MATERIALS AND METHODS}

\subsection{Harvesting Methods and Obtaining Olive Oil Samples}

Olive trees in the Aegean Region of the western part of Turkey were harvested by using the six methods of harvesting; by hand, harvesting by a beating pole on a synthetic fabric, harvesting by a beating pole on a platform, harvesting by a machine on a synthetic fabric, harvesting by a machine on a platform and direct collecting of dropped olives by hand. Olive oil samples were obtained in certain intervals between harvesting and processing. Olive oil was obtained as soon as harvesting was finished. Then, every day for seven days olive samples harvested by six different methods were processed into oil. Until the extraction time, olives were stored in a cold room with $+4^{\circ} \mathrm{C}$ temperature and $70-75 \%$ relative humidity conditions, and during the waiting period, olives were exposed to air. Olive oil samples were processed by using a laboratory type system. This system was designed as similar to big scale olive oil production systems (Fig. 1).

To obtain olive oil by using this system, production steps were carried out as below:

- Separation of dirt and leaves,

- grinding of olives and their pits into paste which goes onto the press,

- malaxation by slow mixing of the paste which allows the oil - water emulsion to coalesce in the malaxation tank that was under constant temperature $\left(30^{\circ} \mathrm{C}\right)$. Small microscopic oil droplets join together into large drops with this process,

- pressing of the paste. The press separates out the olive juice and oil by using an additional filter.

The thermal properties of food show its ability to conduct, store, and lose heat. These properties are inherent to today's food processing and preservation practices. Thermal properties are important for modelling processes (microwave heating, extrusion, freezing, etc.), the engineering design of the processing equipment, calculating the energy demand, and the development of sterilization. Apart from processing and preservation, thermal properties also affect the sensory quality of foods, as well as the energy saving from processing [6]. Kinetic studies speak of the thermal decomposition and thermal stability of the commercial edible oils by using the thermogravimetric method [7]. The obtained results indicate that these parameters were dependent on the composition of fatty acids, being influenced by the presence of natural and artificial antioxidants. According to the thermogravimetric curves, the following thermal stability sequence was suggested: corn $>$ sunflower $>$ soybean $>$ rice $>$ soybean + olive $>$ sunflower + olive $>$ canola $>$ olive; while the activation energy indicated the following stability order: sunflower $>$ corn $>$ soybean $>$ rice $>$ soybean + olive $>$ canola $>$ sunflower + olive $>$ olive. It can be said that according to these results, olive oil that contains unsaturated fatty acids is more unstable compared to others.

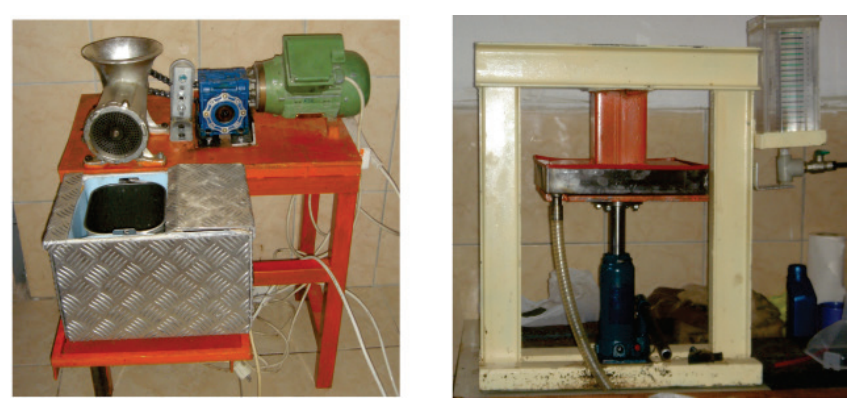

Figure 1 System used to obtain olive oil samples

\subsection{Viscosity Measurements}

In this research, the viscosity of oil samples was measured by using a vibro-viscometer ( $A N D, S V-10$ model). This type of viscometer measures viscosity by controlling the amplitude of the sensor plates immersed in a sample and by measuring the electric current to drive the sensor plates. As seen in Fig. 2, to perform the measurement, thin sensor plates were first immersed into a sample. When spring plates are vibrated with a uniform frequency, the amplitude varies in response to the quantity of the frictional force produced by the viscidity between the sensor plates and the sample.

The vibro-viscometer controls the driving electric current to vibrate the spring plates in order to make uniform amplitude. Since the frictional force of viscidity is directly proportional to viscosity, the driving electric current (driving power) for vibrating the spring plates with a constant frequency to make uniform amplitude is also directly proportional to the viscosity of each sample.

The vibro-viscometer measures the driving electric current to vibrate the sensor plates with a uniform frequency and amplitude, and then the viscosity is given by the positive correlation between the driving electric current and the viscosity (AND company catalogue).

\subsection{Thermal Conductivity Measurements}

KD2 Thermal properties Analyzer (Decagon Devices, Inc., Pullman, WA) that used the line heat source technique was used to determine the thermal conductivity and thermal resistivity values $[1,6]$. The probe length was $60 \mathrm{~mm}$ and its diameter was $1.27 \mathrm{~mm}$. This analyser gives direct readings of thermal conductivity and thermal resistivity with $5 \%$ accuracy.

Thermal conductivity is the ratio of heat flux density to temperature gradient in a material. It measures the ability of a substance to conduct heat.

Thermal resistivity is computed as the reciprocal of thermal conductivity [6]. Namely, it can be formulated as below:

$$
R_{\mathrm{s}}=\frac{1}{k_{\mathrm{s}}}
$$


Where: $R_{s}$ is the thermal resistivity of oil samples $\left(\mathrm{m} \mathrm{CW}^{-1}\right)$ and $k_{s}$ is the thermal conductivity of the sample $\left(\mathrm{W} \mathrm{m}^{-1} \mathrm{C}^{-1}\right)$.

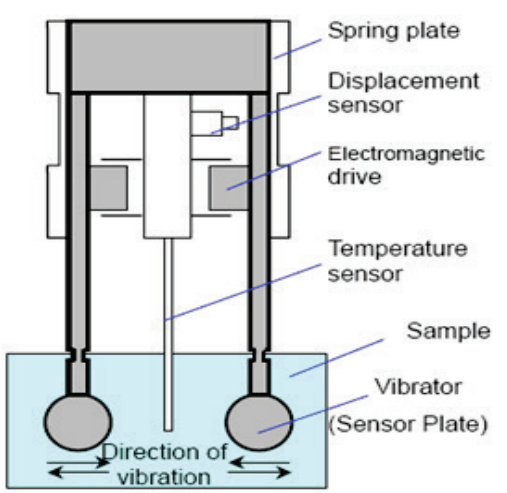

(a)

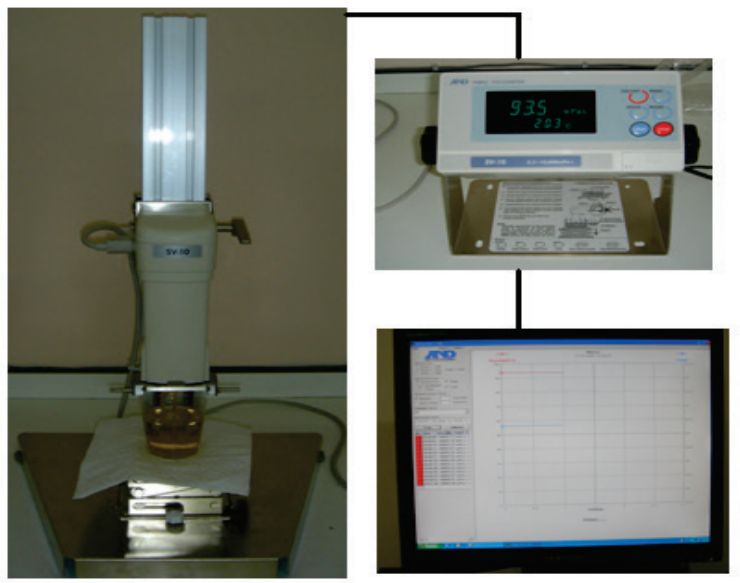

(b)

Figure 2 Detection part of the Vibro-viscometer (AND company catalogue) (a), viscosity measurements of olive oil samples, (b) Measurement steps of viscosity

\section{RESULTS AND DISCUSSION}

According to the measurements performed previously, the dynamic viscosity value of olive oil at $20{ }^{\circ} \mathrm{C}$ is given as $84 \mu \mathrm{Pa} \cdot \mathrm{s}$, while soybean and corn oil viscosity values are $65.69 \mu \mathrm{Pa} \cdot \mathrm{s}$ in the same conditions [8]. As understood from these figures, the viscosity of olive oil is rather high compared to other vegetable oils.
As seen in Tab. 1 and Fig. 3, viscosity values of olive oil samples that were obtained for seven consecutive days after harvesting increased day by day for all samples that were harvested by using a different method. While the viscosity of samples that were obtained on the first day (harvesting day) were found to be almost the same for all harvesting methods; especially the viscosity of oil samples that were obtained by using the spontaneously dropped olives proved to be getting higher compared to others.

Table 1 Results for the dynamic viscosity of olive oil samples as a function of the harvesting method and waiting period

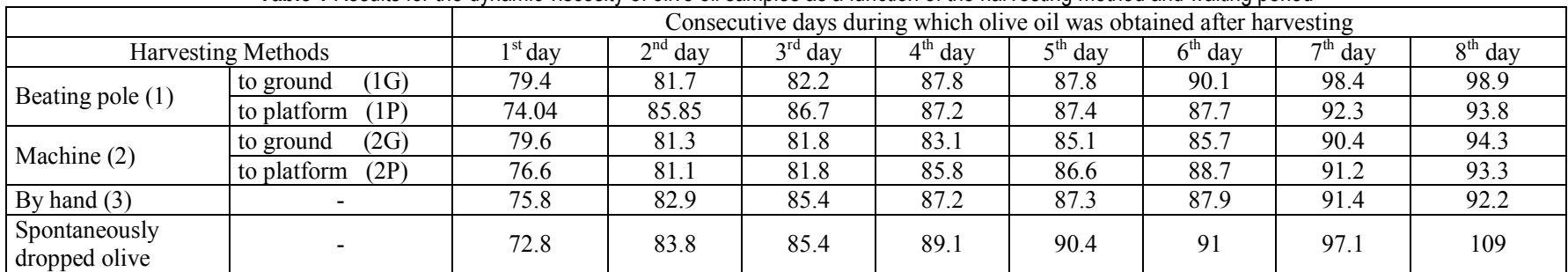

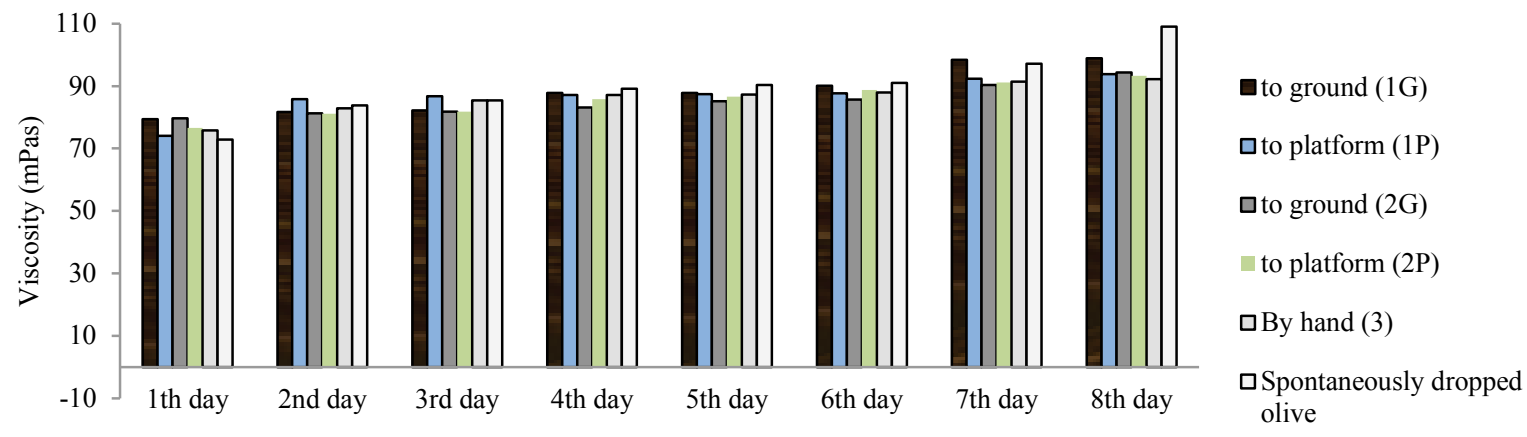

Oil obtaining days after harvesting

Figure 3 Changing of the viscosity values related to the harvesting method and the oil obtaining time after harvesting

As seen in Tab. 1 and Fig. 3, low viscosity values throughout the waiting period were obtained for oil samples that were produced from olives which were collected by hand, harvested using a machine to direct ground and to a special platform. The increase of viscosity values with a waiting period and related to the harvesting method can be explained in the sense that there is a possibility that a protein-polymerised phenol complex (sometimes the culprit 
in a persistently cloudy olive oil), can lead to an increase of viscosity [9]

As seen in Tab. 2 and Fig. 4, thermal conductivity values of oil samples that were obtained just after harvesting were found to be the lowest for all harvesting methods. Conductivity values increased day by day. Lower values were generally found for oil samples that were obtained after harvesting by hand, while bigger values were determined for samples that were obtained from spontaneously dropped olives. These values for olives that were harvested by a beating pole were also found to be generally higher.

Table 2 Results for the thermal conductivity of olive oil samples as a function of the harvesting method and waiting period

\begin{tabular}{|c|c|c|c|c|c|c|c|c|c|}
\hline & & \multicolumn{8}{|c|}{ Consecutive days during which olive oil was obtained after harvesting } \\
\hline \multicolumn{2}{|c|}{ Harvesting Methods } & $1^{\text {st }}$ day & $2^{\text {nd }}$ day & $3^{\text {rd }}$ day & $4^{\text {th }}$ day & $5^{\text {th }}$ day & $6^{\text {th }}$ day & $7^{\text {th }}$ day & $8^{\text {th }}$ day \\
\hline \multirow{2}{*}{ Beating pole (1) } & to ground (1G) & 0.152 & 0.156 & 0.156 & 0.158 & 0.161 & 0.161 & 0.163 & 0.165 \\
\hline & to platform $(1 \mathrm{P})$ & 0.153 & 0.156 & 0.157 & 0.158 & 0.158 & 0.159 & 0.164 & 0.165 \\
\hline \multirow{2}{*}{ Machine (2) } & to ground $(2 \mathrm{G})$ & 0.153 & 0.155 & 0.155 & 0.158 & 0.160 & 0.161 & 0.163 & 0.164 \\
\hline & to platform (2P) & 0.150 & 0.155 & 0.156 & 0.158 & 0.160 & 0.160 & 0.161 & 0.164 \\
\hline By hand (3) & |-------------- & 0.149 & 0.154 & 0.156 & 0.156 & 0.158 & 0.159 & 0.161 & 0.162 \\
\hline $\begin{array}{l}\text { Spontaneously } \\
\text { dropped olive }\end{array}$ & & 0.154 & 0.155 & 0.155 & 0.156 & 0.156 & 0.160 & 0.161 & 0.164 \\
\hline
\end{tabular}

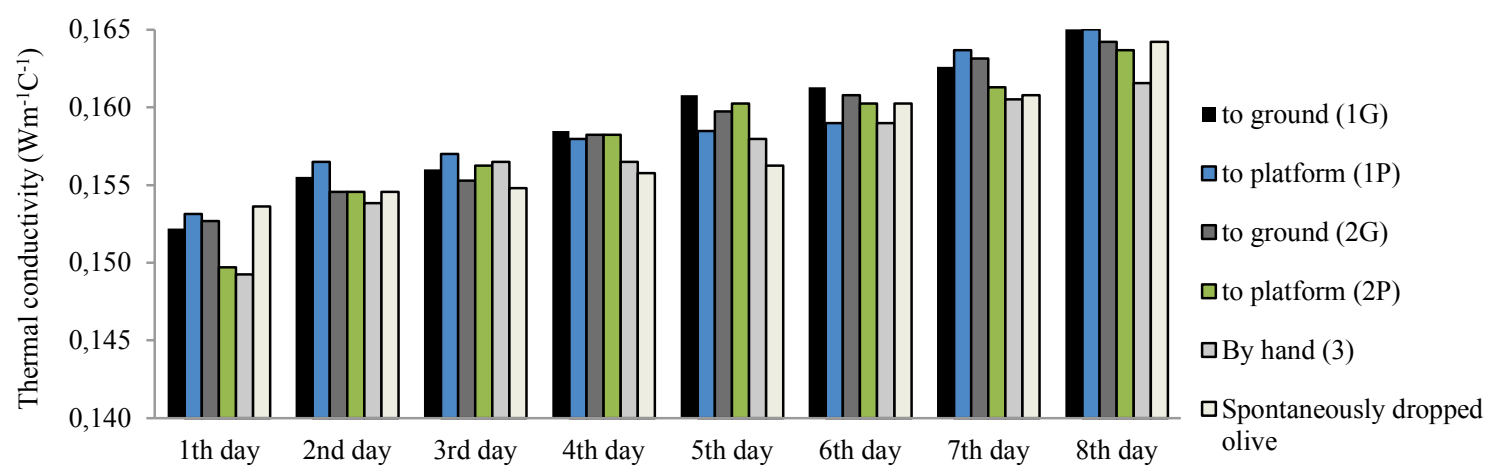

Oil obtaining days after harvesting

Figure 4 Changing of the thermal conductivity values related to the harvesting method and the oil obtaining time after harvesting

Table 3 Results for the thermal resistivity of olive oil samples as a function of the harvesting method and waiting period

\begin{tabular}{|c|c|c|c|c|c|c|c|c|c|}
\hline & & \multicolumn{8}{|c|}{ Consecutive days during which olive oil was obtained after harvesting } \\
\hline \multicolumn{2}{|c|}{ Harvesting Methods } & $1^{\text {st }}$ day & $2^{\text {nd }}$ day & $3^{\text {rd }}$ day & $4^{\text {th }}$ day & $5^{\text {th }}$ day & $6^{\text {th }}$ day & $7^{\text {th }}$ day & $8^{\text {th }}$ day \\
\hline \multirow{2}{*}{ Beating pole (1) } & to ground (1G) & 6.57 & 6.43 & 6.41 & 6.31 & 6.22 & 6.2 & 6.15 & 6.05 \\
\hline & to platform (1P) & 6.53 & 6.39 & 6.37 & 6.33 & 6.31 & 6.29 & 6.11 & 6.06 \\
\hline \multirow{2}{*}{ Machine (2) } & to ground (2G) & 6.55 & 6.47 & 6.44 & 6.32 & 6.26 & 6.22 & 6.13 & 6.09 \\
\hline & to platform (2P) & 6.68 & 6.47 & 6.4 & 6.32 & 6.24 & 6.24 & 6.2 & 6.11 \\
\hline By hand (3) & |------------- & 6.7 & 6.5 & 6.39 & 6.39 & 6.33 & 6.29 & 6.23 & 6.19 \\
\hline $\begin{array}{l}\text { Spontaneously } \\
\text { dropped olive }\end{array}$ & ---- & 6.51 & 6.47 & 6.46 & 6.42 & 6.4 & 6.24 & 6.22 & 6.09 \\
\hline
\end{tabular}

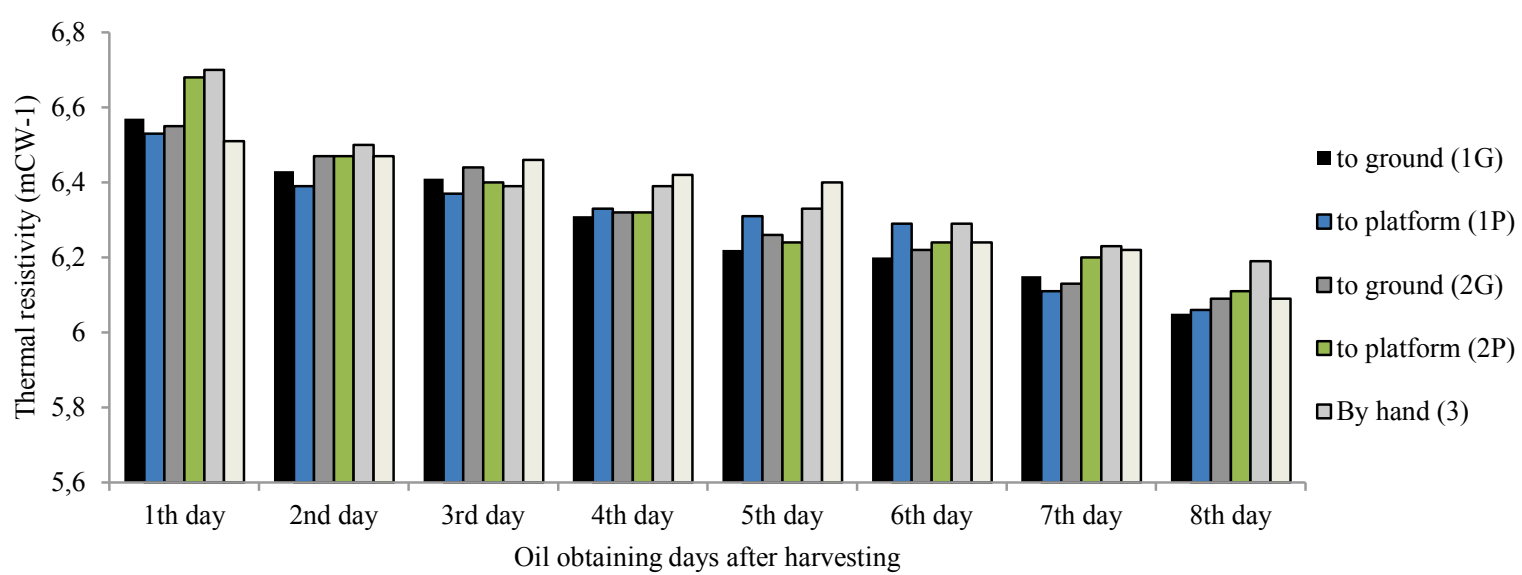

Figure 5 Changing of the thermal resistivity values related to the harvesting method and the oil obtaining time after harvesting 
As seen in Tab. 3 and Fig. 5, the thermal resistivity values of oil samples that were obtained just after harvesting were found to be the highest for all harvesting methods. The resistivity values decreased day by day. Higher values were generally found for oil samples that were obtained after harvesting by hand, while lower values were determined for samples that were obtained from spontaneously dropped olives.

These values for olives that were harvested by a beating pole and a machine (to ground) were also found to be generally lower compared to oil samples that were produced by olives that were harvested by hand and harvested by a machine to the platform.

\section{CONCLUSIONS}

As a result, viscosity, thermal conductivity and thermal resistivity values changed related to the harvesting method and the waiting period after harvesting to obtain olive oil. While viscosity (dynamic) and thermal conductivity values increased with the increase of the waiting time, thermal resistivity values decreased. The lowest viscosity and thermal conductivity values and the highest resistivity values were found for oils that were obtained from olives harvested by hand. The reason behind this situation can be explained in the sense that the percentage of fatty acids in oil samples increased with the increase of the waiting period for olives after harvesting as a result of oxidation due to the exposure of olives to air for a longer time. It can also be said that less bruising occurs on olives that were harvested by hand and a machine (especially the use of a platform to drop olives on it decreased the bruising and tearing of skin).

This situation ensures the prevention of more oxidation of olive trees, which is the oxidative deterioration of these tears on the fruits.

\section{REFERENCES}

[1] Aktaş, T. (2008). The effect of moisture content on the thermal properties of sunflower seeds (Helianthus annus L.). Proc. $36^{\text {th }}$ International Symposium Actual Tasks on Agricultural Engineering, February 11-15, 2008, Opatija, Croatia.

[2] Brock, J., Nogueira, M. R., Zakrzevski, C., Corazza, F. C., Corazza, M. L., \& Oliveira, J. V. (2008). Experimental measurements of viscosity and thermal conductivity of vegetable oils. Ciência e Tecnologia de Alimentos, 28(3), 564570. https://doi.org/10.1590/S0101-20612008000300010

[3] Cemeroğlu, B. (2005). Basic Processes in Food Engineering. Food Technology Society Publications, 29, Ankara. (in Turkish)

[4] Dag, A., Ben-Gal, A., Yermiyahu, U., Basheer, L., Nir, Y., \& Kerem, Z. (2008). The effect of irrigation level and harvest mechanization on virgin olive oil quality in a traditional rainfed 'Souri' olive orchard converted to irrigation. J Sci Food Agric, 88, 1524-1528. https://doi.org/10.1002/jsfa.3243

[5] Garcia, J. M. \& Yousfi, K. (2006). The postharvest of mill olives. Grasas Y Aceites, 57(1), 16-24. https://doi.org/10.3989/gya.2006.v57.i1.18

[6] Fontana, A. J., Wacker, B., Campbell, C. S., \& Campbell G. S. (2001). Simultaneous thermal conductivity, thermal resistivity, and thermal diffusivity measurement of selected foods and soil. ASAE Annual International Meeting, California, USA, July 30-August 1, 2001, Paper Number 016101. https://doi.org/10.13031/2013.5543

[7] Santos, J. C. O., Dos Santos, I. M. G., De Souza, A. G., Prasad, S., \& Dos Santos, A. V. (2002). Thermal stability and kinetic study on thermal decomposition of commercial edible oils by thermogravimetry. Journal of Food Science, 67, 1393 1398. https://doi.org/10.1111/j.1365-2621.2002.tb10296.x

[8] http://hypertextbook.com/physics/matter/viscosity/

[9] http://www.savantes.com/articles/OBGuest/Oth/olive_oil_ fatty_acid_profiles_an.htm

\section{Authors' contacts \\ Cihangir SAĞLAM, Corresponding author Department of Biosystem Engineering, Faculty of Agricultural Namik, Kemal University, Tekirdag, 59030, Turkey \\ E-mail: csaglam@nku.edu.tr}

Fulya TAN,

Department of Biosystem Engineering,

Faculty of Agricultural Namik,

Kemal University, Tekirdag, 59030, Turkey

Türkan AKTAS,

Department of Biosystem Engineering, Faculty of Agricultural Namik,

Kemal University, Tekirdag, 59030, Turkey 